\title{
POETAS DEL 68... DESPUÉS DE 1975
}

\author{
Ángel L. Prieto DE PAUla \\ Universidad de Alicante
}

\section{«QQué fue de tanto galán?», o lo que queda del 681}

Por el título de esta exposición, se entiende que trato de presentar aquí lo que quedó de aquel fuego nuevo sesentayochista -Castellet dixit- una vez que habían pasado las condiciones históricas en que surgió, aceptando implícitamente que ese fuego existió, y que de él dan testimonio todavía hoy algunas pavesas, que comparten el escenario con las de poetas más jóvenes y estéticas ulteriores. Pero aclaro enseguida que no me interesa colegir, a partir de las cenizas, las dimensiones de la hoguera sesentayochista; sino saber si aquello fueron fuegos fatuos, o si de verdad constituyó un incendio en el que quedaron calcinados muchos de los valores de la cultura antigua, y correlativamente instaurados otros que, con cuantas actualizaciones y adecuaciones sean del caso, habrían de llegar hasta el siglo XXI. Porque, si es así, importa sólo relativamente -aunque aquí nos refiramos a ello- qué ha pasado con este o con aquel poeta, cómo han evolucionado unos y otros, quiénes que fueron ya no son, quiénes son de los que no estaban, y quiénes no son porque nunca fueron, aunque estuvieran durante unos años, siempre demasiado efimeros. Lo que importa de verdad es precisar los caracteres que dieron una impronta determinada a aquellas poéticas, cuáles de ellos han dejado un surco perceptible en la poesía española del último cuarto del siglo Xx, y de

' La parte correspondiente a este epigrafe sirvió de base para la conferencia de inauguración que, con su mismo título, pronuncié en el Congreso Internacional «Poéticas Novísimas», celebrado en Zaragoza del 24 al 27 de abril de 2002. 
qué elementos retóricos y constructivos se valieron los autores para constituir un nuevo lenguaje.

Bien sé que, antes de proseguir, hay que derribar un muro cuyo grosor y consistencia son muy considerables. Me refiero a la actitud divinista de los que entienden la poesía, preferente o exclusivamente, como una creación que sólo puede dar cuenta de un psiquismo individual, desvinculado del contexto social y de la misma historia, como una realidad ucrónica con las raíces temporales al aire.

La Revolución Industrial aparcó a los poetas en unas hornacinas ad hoc, lejos del dinamismo de una sociedad que en muy pocos años había subvertido la pauta de sus valores, quizá como no lo había hecho desde la revolución neolítica. Apartados del mercado de los valores al uso, en un mundo donde, como en la República platónica, los poetas ya no tenían un sitio al sol, éstos terminaron escapándose con despecho precisamente adonde los habían desterrado los sacerdotes de la tecnolatría. Haciendo de la necesidad virtud, a partir del Romanticismo la poesía ha insistido en su entidad olímpica, y, a medida que se iba acentuando su invisibilidad, muchos poetas enfatizaban, con la fanfarronería del miles gloriosus, la condición irrestrictamente individual de su arte, no sometido a mediatizaciones de época ni de grupo. Nada más frecuente, cuando se trata de este tema, que oír las diatribas contra quienes osan referirse a los poetas como a un hatajo, banda o panda generacional. ¿Qué tiene que ver, unos ejemplos entre otros, Martínez Sarrión con Clara Janés, qué tiene que ver Gimferrer con Aníbal Núñez, Jenaro Talens con Lázaro Santana, Vázquez Montalbán con Paloma Palao? En este punto, quienes aparecen como culpables de tender a la indiscriminación repliegan a menudo velas y exteriorizan justificaciones, declarando que, en efecto, tales autores nada tienen que ver, y que sus propios pecados generacionales han sido cometidos por no sé qué exigencias profesorales que les hacen renunciar a la particularización y considerar gregariamente a los poetas en capazos colectivos, generacionales o estéticos, en aras de los intereses pedagógicos y de las obligadas taxonomías historiográficas.

En el fondo, los que así piensan consideran que la del poeta es una sensibilidad de bulto redondo en cuya constitución no hubieran dejado su impronta las señales de un tiempo histórico. La existencia de esa impronta de época, habrá que decir como si la perogrullada fuera un descubrimiento, no adocena a los poetas, sino que les ofrece su acervo de valores vigentes, de mitos temáticos y hasta de construcciones retóricas para que cada cual mimetice, o module, o disienta, o rechace. Ese universo común queda luego contraido a la médula individual, y, en el caso de los poetas importantes, es expresado con unas palabras que, por su pertinencia y su intensidad, dejan de ser las palabras de la tribu aunque hayan sido extraídas del diccionario de la tribu. 
De todos los valores de época que, en los años de su formación, constituyeron la taracea espiritual sobre la que se fragua la voz personal de los distintos autores, destacan algunos a los que quisiera referirme. En primer lugar, y desde el punto de vista de la actitud predominante, estaría la desconexión emotiva entre el poeta y la materia del poema: ésta deja de entenderse como emanación de aquél; una emanación directa y, en la acepción filosófica del término, necesaria. Esta desconexión sensitiva es fruto de un repudio de la abusiva identificación entre lirismo y emoción sentimental, que había conducido a la idea del poema como una suerte de evisceración espiritual. Y si los del medio siglo habían condenado la confusión entre tema y poema -«Cuántos temas justos y cuántos poemas injustos», escribió Claudio Rodríguez a este particular (en Ribes, 1963: 91)-, los sesentayochistas hicieron otro tanto respecto de la existente entre tema y autor: una confusión a la que condujo la institucionalización y la mineralización de las propuestas románticas. Éste es el motivo de que proliferaran los recursos para desviar o desleír la inmediatez afectiva y la emoción primaria (Prieto de Paula, 1996: 105-117).

Una característica conectada con la anterior consiste en el arrellanamiento de estos poetas en un universo en el que hacía ya un tiempo se había producido la quiebra de la razón discursiva, la demolición de referentes filosóficos y, como consecuencia, la suspensión de las certezas a que había conducido el fracaso del logocentrismo. He dicho arrellanamiento, con su idea inherente de acomodación y pliegue a las escarpaduras del statu quo, de donde deriva, como se verá, el particular y más original modo de dicción de estos poetas. Es claro que ese mal de la contemporaneidad no nacía con ellos, puesto que, con anterioridad, varias generaciones habían ido propiciando una progresiva aclimatación a ese desarbolamiento filosófico, a esa oquedad metafísica de vocación propagativa. Por eso la expresión literaria de estos autores no usó por lo general los registros de la compulsión, la exasperación, la deflagración patética o la distorsión expresionista, que son los modos retóricos en que tradicionalmente se había manifestado la desazón existencial. Es cierto que determinados poetas parecen acreditar lo contrario, pero se trata de un obstáculo menor. Por citar algún ejemplo, la pasión de Antonio Carvajal en Tigres en el jardín (1968) resulta no contradicha, pero sí aliviada artísticamente, por las gasas de los alejandrinos de filiación modernista, algo que se acentuaría en Casi una fantasía (1975), en que dicha pasión aparece más desvaída aún en la máquina barroca de los sextetos. Y, mutatis mutandis, las imágenes expansivas de Sepulcro en Tarquinia (1975), de Antonio Colinas, que van generando brotes tropológicos cada vez más desvinculados de la desgraciada historia de amor que se nos refiere, cumplen parecida función. La propia presencia invocada de Modernismo y Barroco en aquel caso, y de fervor romántico en 
éste, contribuye por paradoja a acentuar la condición de artificio poético de las respectivas obras.

En realidad, el proceso de relajación de las formas del patetismo venía de antiguo: ya la absorción del mal du siècle decimonónico había propiciado el tránsito de la desesperación romántica a la desesperanza finisecular. En esta ocasión se avanzaba desde el tremendismo agonístico de unas décadas atrás hacia la displicencia, la atenuación de la taxatividad mediante la lítote o las sinuosidades ensayisticas, la racionalidad laberíntica, la quiebra del dogmatismo...: modos, todos ellos, de impedir que un universo del que ya hacía tiempo se habían distanciado los dioses hasta desaparecer fuera expresado por formas poéticas caracterizadas por el arrebato o el enardecimiento (Prieto de Paula, 1996: 118).

Y una tercera característica se referiría a la pérdida de una suerte de expectativa teleológica respecto del poema y de la propia actividad poética. ¿Sirve ésta de algo? Para la mayoría de lo sesentayochistas -acoto: de los sesentayochistas en el 68 - la poesía es una creación que no se explica desde fuera, sino en sí y por sí. Su sentido no depende ni deriva de su función social, de su vinculación con el contexto, de la nobleza de los temas, de la entidad del autor. Por todos los lados aparecían apelaciones a la falta de concordancia entre el arte y la vida no específicamente literaria, a la intrascendencia de la poesía, a su condición de mester profesional, incluso a su inanidad. En sus respectivas poéticas a Nueve novisimos, Vázquez Montalbán afirmaba que «la poesía, tal como está organizada la cultura, no sirve para nada» (en Castellet, 1970: 59); José María Álvarez aludía a la escritura como juego, y confesaba que su verdadera vocación era «jugador de billar o pianista» (ibid.: 111); a Ana María Moix lo que le gustaba era piruetear en un trapecio o, cuando no, «tocar la trompeta en una calle oscura» (ibid.: 122). Una afición musical ésta compartida por Carnero, quien se encaminó por las sendas de su «auténtica vocación» tras la llamada de lo sicalíptico, que se produjo muy de niño, cuando era acunado por su abuela con las tonadillas de La Corte del Faraón (ibid.: 116-117). El alarde desacralizador, que entonces parecía ingenuamente escandaloso, hoy nos parece escandalosamente ingenuo, y confirma, creo, lo que se venía señalando.

Esta desacralización no se limitaba al ámbito de la creación poética, sino que afectó a la teoría sobre ella, y lo hizo incluso con el propio antólogo de los novísimos, Castellet, que en la dedicatoria de su compilación a la jovencísima Ana María Moix simulaba una senectud esteticista (ibid: : 7). En la dirección de considerar el poema como un objeto que manifiesta ontológicamente su propia incapacidad de significación, camina la idea barthesiana que hace del metadiscurso crítico una parte inherente al propio discurso literario, y para la cual el texto es una galaxia de significantes que pueden conducir a la plurisignificación ilimitada. La acumulación de lecturas que se producen sucesivamente en el eje de 
la diacronía, generación de lectores tras generación de lectores, según los estudios de la escuela de Constanza sobre la estética de la recepción, está, en fin, en un espacio del que no resulta alejada la definitiva destrucción del texto e incluso la negación del autor. Era poco después de 1970 cuando Umberto Eco, un teórico tan presente en el prólogo de Castellet, defendía en Le forme del contenuto el relativismo significativo, no situado precisamente en los antípodas de la idea de semiosis infinita, como ésta tampoco lo estaba de la negación de todo sentido que propone la desconstrucción.

Cuando irrumpieron los novísimos castelletianos en el panorama poético español, se generó un sarpullido en la sociedad literaria cuyos efectos persistieron durante mucho tiempo. Resultaba extraño que un crítico como lo era Castellet adoptara la postura de un promotor artístico, y que un prólogo compatibilizara la propuesta estética con el diagnóstico de una situación. No es ésta la ocasión de desglosar y comentar los rasgos que contribuyeron más decisivamente a pergeñar una poética plural de todas formas: culturalismo, irracionalismo, espontaneidad naïve, nueva mitología de procedencia extraliteraria... y hasta algunos ecos del realismo, sólo que tamizados por una sensibilidad camp, que usaba con sabia ambigüedad los emblemas populares para mostrar el rechazo de la sociedad en que surgieron. Ése es el sentido de cierta mítica novísima que, aunque de sabor españolero, no exige la adhesión emotiva tan patente, por ejemplo, en el pseudolorquismo de toreros y folclóricas. Los mismos núcleos míticos aparecían, en unos casos, sublimados por la cultura, y en otros condenados por una cultura de signo distinto. Algo parecido había ocurrido mucho antes en el enfrentamiento entre el popularismo vanguardista de hacia 1930 -Sánchez Mejías como símbolo- y el que resultó de su aclimatación a la costra franquista de los años cuarenta -la tanatofanía a propósito de la muerte del también torero Manolete-.

Sobre las líneas dominantes de esta estética pesó desde el principio una condena en la que parecían hacer causa común los representantes de la España de «cerrado y sacristía» con quienes reclamaban una apertura artística y social de otro tipo. Ejemplo de estos últimos son los redactores de la revista leonesa Claraboya, que en 1971 publicaron Teoria y poemas. En una actitud similar a la que casi treinta años atrás habian mostrado sus predecesores leoneses de Espadaña frente a los garcilasistas y sus zalemas endecasilábicas, los de Claraboya vieron en los nuevos poetas a unos jóvenes cachorros de la burguesía catalana, que propugnaban insolentemente el rebrote de una estética inerte. Ello les convirtió en destinatarios del venablo de Carnero, quien habló del «marxismo de secano» de sus impugnadores (Carnero, 1978). «Marxismo de secano» es, precisamente, el título de uno de los artículos publicados en las páginas literarias de Pueblo entre 1978 y 1979 -luego reunidos en el libro Las cenizas del Fénix-, firmados por el inexistente «Sabino Ordás», que pasaba por ser un viejo republicano recupe- 
rado del exilio, cuya trayectoria vital habían urdido ingeniosa e hilarantemente Juan Pedro Aparicio, Luis Mateo Díez y José María Merino, vinculados a aquella Claraboya que fue la única disensión organizada contra la antología de Castellet. Al tal «Sabino Ordás», heterónimo colectivo de los tres leoneses citados, se le hacía escribir: «Consagraba aquella antología, de cuatro barceloneses, dos valencianos y tres comparsas, una larga teoría de ecuaciones cuyo enunciado pudiera ser más o menos éste: Lo Barcelona = Lo Veneciano = Lo Marilyn = Lo Elegante $=$ Lo Periférico $=$ Lo Bello. Mas como su sistema era maniqueísta, establecía al tiempo una teoría antónima: Lo Estepario $=$ Lo Mesetario $=$ Lo Interior $=$ Lo Feo $=$ Lo Marxista $=$ Lo Secano $»^{2}$. Así que no es extraño que luego, con intenciones más ridiculizadoras que pedagógicas, las situaciones quedaran varadas en una simplificación en que la literatura tenía ya poco que ver: novísimos frente a socialrealistas, venecianos frente a manchegos, el sándalo frente a la berza.

Los antologados por Castellet no fueron inocentes en este proceso, a cuya difusión contribuyeron activamente con el prestigio que dan por procuración cátedras, editoriales y academias, a las que algunos accedieron pronto. Opinando no ya como impetuosos poetas emergentes, sino como sesudos historiadores de su empresa juvenil, propalaron que su lucha había sido contra una poesía de temática ramplona y lenguaje instrumental; en suma: contra la poesía de postguerra, a la que condenaron sin pestañear, como si vieran en ella una metonimia de «lo español», corrompido inexorablemente por el franquismo.

Pero las injusticias no siempre se eternizan, y menos aún cuando los autores del medio siglo, que a la sazón estaban en su plenitud, seguían imperturbables publicando algunos de los libros más intensos de sus respectivas trayectorias y de todo el período. Tampoco convendría que se dilatara en el tiempo otra injusticia, que no lo es menor que la anterior aunque quizá más justificada psicológicamente: la que considera cerrado el espíritu sesentayochista tras la inflexión que se produce en torno a 1975-1978, y nada se diga del momento en que la poesía se decanta hacia otros derroteros estéticos por los años 1982-1985. Así que no es cierto que muchas pretendidas innovaciones sesentayochistas carecieran de precedentes, y hasta es una zafiedad intelectual pretender aplicar, como una camisa de fuerza, el referencialismo documental o realista a muchos de los poetas de los cincuenta (y ello sin dar por sentado que tales títulos sean intrínsecamente perversos), para mostrar la originalidad de lo que vino después. No insistiré sobre ello, que resulta ya muy evidente. Menos explicado está lo concerniente a la desvinculación de la

2 El artículo al que pertenece la cita («Marxismo de secano») apareció en Puehlo, 20 de abril de 1979; recogido en Sabino Ordás (el personaje creado por Juan Pablo Aparicio, Luis Mateo Díez y José Maria Merino), Las cenizas del Fénix, León, Diputación, 1985, pp. 174-175. 
poética de los ochenta respecto de la sesentayochista: como si alguna corriente poética pudiera explicarse prescindiendo de la precedente.

Que no es así resulta cada vez más claro, y nos obliga a poner en cuestión en todos los casos la posibilidad de que la poesía pueda ignorar su interna concatenación. El tópico histórico-crítico se ha referido en numerosas ocasiones a una oscilación pendular mecanizada: a la atracción del caos sucedería la del orden, a la del normativismo prescriptivo la del individualismo insurgente, etcétera. Pero, si se prescinde de estas bizarras simplificaciones, notaremos que cada movimiento del péndulo hacia un lado arrastra muchos de los constituyentes de la estética de donde partió. Es cierto que, a medida que estos novísimos iban perdiendo el apresto de la novedad y entraban en sazón -algunos dirán que en razón-, el exotismo culturalista, que en su día reflejó su desdén por el entorno cercano, persistía ya casi sólo como excipiente de la indagación metapoética y de la historia personal. Unas veces, la obturación de los conductos de la razón discursiva propiciaba una poesía que se deshace al fin en una verbena de luminarias apocalípticas (Leopoldo María Panero); otras, el alambicamiento textual hacía pasar por irracionalismo lo que en realidad era una exacerbación laberíntica de la razón discursiva (Carnero, Talens); algunas, la poesía apelaba a la tradición surrealista (Gimferrer), la última deriva de la música wagneriana de la opacidad del ser, a la que asimiló Antonio Machado la poética simbolista que estaba en su origen; otras, en fin, tendía a la regresión esencialista, hacia la mandorla de una verbalización retraída hasta el hueso, donde los significados se comprimen en una mera denotación objetual (Sánchez Robayna), o se asentaba en un escepticismo gnoseológico, muy lejos de la literatura como confirmación de un sistema nocional previo (Aníbal Núñez).

Las voces de quienes se incorporaron a la publicación tras la muerte de Franco -Jesús Munárriz, Sánchez Rosillo, Francisco Bejarano, Abelardo Linares, incluso varios años después, venian a sumarse a las de quienes, como Juan Luis Panero o Miguel d'Ors, en 1975 empezaron a gozar del predicamento que antaño se les había negado; y también a las de quienes, procedentes de las antiguas trincheras, se pasaron con armas y bagajes hacia una poesía más transitiva, o realista, o autobiográfica, o todo ello a un tiempo, pero en cualquier caso apeada del coturno culturalista: sirva el nombre de Luis Alberto de Cuenca como paradigma, a partir de La caja de plata (1985).

Así las cosas, la estética sesentayochista parecía haber perdido su preeminencia en el panorama literario. Frente a ella se erigían poetas nuevos, coetáneos o más jóvenes, cuya disidencia fue apuntalada también por la evolución natural de los primeros sesentayochistas. Quienes, como Colinas, acreditaban una filiación romántica que no había aceptado las cautelas, los filtros irónicos y el distanciamiento de otros coetáneos, encontraban ahora lectores entregados a una idea numénica de la poesía. Al lado de ellos comenzaban a crecer autores jóvenes 
que parecían aportar una novedad que tampoco lo era, ni siquiera relativamente, basada en la fragmentación del yo, el sujeto multiplicado, el desleimiento, en fin, de la voz autorial en las diversas voces de la representación. Me refiero a la condición de la poesía como texto ficcional, próximo a la dramatización que vertebra la poesía de la experiencia anglosajona. Esta característica, según la propusieron los autores de «la otra sentimentalidad», había sido ya enarbolada por los grandes nombres del 68. Ahí están los recursos de la teatralidad y de las máscaras, los correlatos objetivos, el personaje histórico analógico de tantos y tantos poetas, de tantos y tantos poemas.

¿De dónde proviene, entonces, la impresión de hiato tajante entre los sesentayochistas y quienes les sucedieron en la primera plana del escaparate literario, si es cierto que comparten muchas más cosas de las que creíamos? Apuntaré sólo un par de ellas que no comparten. En primer lugar, la asunción de la lección vanguardista. Frente a los denominados poetas de los ochenta, que consideraron las vanguardias como un producto amortajado ya en las historias de la literatura, los sesentayochistas no se abrazaron acríticamente al producto de las vanguardias, pero tampoco abjuraron de una actitud rupturista que les hizo empeñarse en la búsqueda de un nuevo lenguaje. A efectos de esta búsqueda, la mera denotación representativa que da cuerpo a buena parte de la poesía más joven, o la mimetización del simbolismo de inicios del Novecientos, se manifiestan como insuficientes. $Y$ eso no ha cedido, sino todo lo contrario, en libros bien recientes como Mascarada, de Gimferrer, Teoría del miedo, de Leopoldo María Panero, o Verano inglés, de Guillermo Carnero.

La segunda razón de esta separación es la importancia tan distinta que han tenido en su obra los avatares biográficos. La poesía de la experiencia de los años ochenta partía de la inexistencia de pautas filosóficas generales, y colocó en lugar de aquéllas los incidentes, livianos o anecdóticos, de sus particulares biografías como manifestación del orgullo de lo circunstancial y lo precario, ocupando el sitio que habían dejado vacante los grandes sistemas eudemonológicos. No nos cebaremos ahora en la banalización a que se redujo el ejercicio poético en el caso de los epígonos menos dotados, que encumbraron lo poéticamente adventicio: se trataría de una sinécdoque injustísima, consistente en confundir el todo con la peor de las partes. Los del 68, por su lado, mantuvieron cerradas las esclusas de la intimidad concretada en la anécdota biográfica, aunque ello les supusiera su reclusión en el cajón hermético de un tipo de poesía cuya autorreferencialidad, o como mucho su referencialidad acotada a los temas de una realidad filtrada en diferentes cedazos, le vedó el acceso a los grandes públicos.

Si nos repitiéramos ahora la pregunta manriqueña del epígrafe, «¿Qué fue de tanto galán?», habríamos de decir que en los libros últimos de muchos de ellos permanece encendido ese fuego nuevo al que antes aludíamos. Más aún, cuan- 
do maliciosamente se escribe o se propala la especie de que aquello fue humo de pajas, apostillaré que incluso en la renuncia a la poesía que tantas veces se ha aducido para tratar de hacer visible la vacuidad de las propuestas iniciales, puede intuirse la entidad y mantenimiento de las mismas, aunque sea por la vía radicalmente negativa, pero también cerradamente coherente, del abandono de la escritura.

Pero veamos el recorrido de algunos autores del 68 , tanto de la primera hornada como de las posteriores, para apreciar de qué modo incide un determinado sentido del devenir histórico y cultural en la evolución estética de los individuos.

\section{La evolución de los primeros sesentayochistas}

A la altura de 1975, la mayoría de los poetas del 68 mostraba ya rasgos no homologables a los de unos años atrás. Algunos autores ejemplifican las principales líneas de evolución en este período. Pere Gimferrer (1945) es el que de manera más persistente fue construyendo una obra asumida como modelo por muchos escritores coetáneos. La riqueza de la obra gimferreriana responde a la pluralidad simultaneísta del poeta, de quien se nos revelan diversas personalidades - personue, 'máscaras'- bajo un armazón estructural y lingüístico que da cohesión al conjunto. A la misma contribuyen elementos persistentes en él como la indagación en una conciencia individual, la consideración de la vida bajo especie literaria, y una idea del amor que puede ser nostalgia de plenitud, metáfora del conocimiento o reflexión frente a la cada vez más neta conciencia de la muerte. Estéticamente nos hallamos ante un autor de base simbolista, con derivaciones surreales que lo han liberado de la esclavitud realista. Excluidos sus títulos iniciales-Malienus se escribió en 1962, aunque el primero publicado es Mensaje del Tetrarca (1963)-, en Arde el mar (1966) ya aparecía desarrollado su resplandeciente verbalismo, encarnado el procedimiento de los correlatos objetivos y maduro su sistema de plasmación visual de los conceptos, cualidades que se mantendrían en La muerte en Beverly Hills (1968), donde asoman los rostros de la desolación entre los motivos cinematográficos. Su abandono del castellano como lengua para la poesía data de 1970, con El miralls. Tras títulos como Hora foscant y Foc cec, el autor dio a la luz L'espai desert (1977), donde la intensidad con que se enunciaba la tensión del amor, el sexo o la palabra creadora parecía haber topado con un muro. El silencio creativo augurado en ese libro llegó tras Com un epileg (1981; en Mirall, espai, aparicions), aunque el polimorfismo psíquico de este poeta le permitió resurgir con nuevos títulos que conducirian hacia una obra de plenitud como Mascarada (1996), en que su poesia, ahora más enjuta y ascética, restalla en los casi quinientos eneasílabos sin puntuación, por donde van y vienen pulsiones eróticas, compromisos cívicos, imágenes calcinadas de la sobrerrealidad, todo 
ello a horcajadas entre el pasado de la evocación y el presente de la escritura. $E l$ diamant dins l'aigua (2001; en edición bilingüe en 2002) es más heterogéneo y dispersivo, con composiciones amorosas sentimentalmente explícitas y cantos de despedida, aunque el poema principal, que da nombre al libro, parece producido por una máquina de rimar: formado por ciento ochenta y dos versos en redondillas de eneasílabos con rima consonante fija, la evidencia del mecanismo sonoro oculta la lógica semántica de los versos. A partir de 1975, en años de regresión novísima, se mantuvo la importancia y la condición arquetípica de Gimferrer entre los coetáneos y los poetas y lectores más jóvenes; pero ya había dejado de ser un estandarte estético tras el que otros apretaban filas.

Guillermo Carnero (1947) había conseguido en Dibujo de la muerte (1967) una simbiosis temática entre belleza y muerte de superficie culturalista, trasfondo barroco y caligrafía parnasiana. El arte aparecía allí como un sucedáneo de la realidad, cuyo resultado es la grandiosa escenificación de una tanatofanía, frente a una vida gobernada por el sinsentido y por un dinamismo estéril. Con ese arranque, Carnero fue abandonando cualquier proclividad sentimental, por una senda de asepsia denotativa y sinuosidades argumentativas de registros filosóficos y científicos. Libros como El sueño de Escipión (1971), Variaciones y figuras sobre un tema de La Bruyère (1974) y El azar objetivo (1975) se adentraban, en clave metapoética, en la zona de intersección entre la realidad y el lenguaje. El reconocimiento de la mezquina conversión de la experiencia vital en belleza artística dio paso a la negación de un lenguaje en exceso consciente y sustitutorio de la realidad, lo que le condujo a la aridez posterior a El azar objetivo, el libro en que había desplegado, con un discurso paradójicamente inflado, las carencias del logocentrismo. De esa afasia, interrumpida por excepción al reunir su obra en Ensayo de una teoría de la visión $(1979,1983)$, sólo salió quince años después con Divisibilidad indefinida (1990), que engloba un cuaderno aparecido un año atrás, donde la emoción que había tan inmisericordemente extirpado vuelve a presidir el arte de la poesía. Ya para entonces recobraba el lenguaje su primer esplendor sensorial y aparato arquitectónico para dar cauce, en la cárcel del soneto clásico, a los motivos de la desolación barroca. La plenitud del sentimiento, amoroso en este caso, estalla en Verano inglés (1999), cuyo muelle hedonismo, fundado en las referencias de la pintura erótica del XVIII, se aboca a la renuncia existencial correspondiente a los interiores zurbaranescos. Las consideraciones sobre el acabamiento de la pasión se desarrollan en Espejo de gran niebla (2002), cuyo simbolismo acuático recrea el ámbito del desconsuelo resultante del fracaso de la experiencia del ser, que sólo admite una pálida representación mediante los engaños de la evocación y del lenguaje.

En una línea en parte afín a la del Carnero metapoético cabe situar a Jenaro Talens (1946), quien en diversos títulos tardíos -El cuerpo fragmentario (1978), 
Otra escena. Profanación(es) (1980), Tabula rasa (1985), La mirada extranjera (1985)...; y asi hasta Viaje al fin del invierno (1997), Profundidad de campo (2001) y Minimalia (2001) - da las notas más afinadas de su trayectoria poética, al conseguir que el rigor de siempre se vertebre en un discurso lleno de aristas de luz, donde aparecen como elementos nucleares la condición del lenguaje como realidad él mismo, y la inquisición acerca del propio sujeto.

Un escritor que no ha abandonado su apuesta radical y que ha mantenido intacto el nudo de sus obsesiones es Leopoldo María Panero (1948), arquetipo de un malditismo cultivado tanto como repudiado, sin membrana entre vida y literatura. Rodeado de poesía por todas partes -es hijo y sobrino, respectivamente, de Leopoldo Panero y Juan Panero, y hermano de Juan Luis-, ascendió a categoría mítica a partir de la película de Jaime Chávarri El desencanto (1976), donde hermanos y madre procedieron a una exhumación de las miserias familiares que alcanzó la grandeza de una vanitas barroca. Cercano a Genet, a Kafka, a Trakl, su obra ha desvelado los tabúes de nuestra cultura: postrimerías, homosexualidad, drogas, incesto, coprofilia, necrofilia, blasfemia. Si se excluye un cuaderno de 1968, su primer libro publicado, de 1970, es Asi se fundó Carnaby Street, continuado por Teoría (1973), donde ya se apreciaba el fragmentarismo, la desconstrucción y una lucidez negativa más apropiada para el relámpago poético que para el discurso racional. Sin embargo, la linealidad del avance en esta poesia se interrumpe hacia 1980. Uno de los libros importantes del período es Narciso en el acorde ilttimo de las flautas (1979), en cuya estética parece embarrancar el poeta sin posibilidad de progreso. Libros posteriores, como El último hombre (1984) o Poemas del manicomio de Mondragón (1987), o más tardíos, como Contra España y otros poemas no de amor (1990), Piedra negra o del temblar (1992), Teoría (2000), Prueba de vida. Autobiografia de la muerte (2002) o Buena nueva del desastre (2002), así lo demuestran. El sujeto da unidad a los sucesivos libros, contrarrestando la discontinuidad de las imágenes y los cortes del discurso, pese a que él mismo es un sujeto fragmentado, que cuestiona a menudo la propia idea de autoría. La escritura de Panero, que nos remite a un universo regido por el mal y el sinsentido, es, a la postre, fulgurante y falta de construcción. La atracción que suscita esta obra abismática y descoyuntada proviene en buena medida de un malditismo que asoma como reliquia del tiempo en que, en palabras de Félix de Azúa, «el oficio de poeta implicaba llevar una vida ejemplar». La obra de Eduardo Haro Ibars (1948-1988) puede considerarse dentro de esta misma tendencia de ácida vocación autodestructiva. Iniciada con Pérdidas blancas (1978) y clausurada con En rojo (1985), esta poesía es el vestigio de una vanguardia que ya resulta anacrónica en la ciudad posmoderna, de la que el autor da cuenta en unos versos conmovedores por su contundencia y abrasados por el fulgor negro de sus imágenes. 
Otro de los novísimos castelletianos, Antonio Martínez Sarrión (1939), representa la síntesis entre el paradigma sesentayochista más conocido, con inclinaciones experimentalistas y vanguardistas, y la poesía crítica de talante civil de generaciones anteriores. Si excluimos, de entre su obra anterior a 1975, Teatro de operaciones (1967), una evocación de la infancia donde registra su educación sentimental en el contexto de la postguerra, sus títulos propiamente sesentayochistas son Pautas para conjurados (1970) y Una tromba mortal para los balleneros (1975), libro el último que desintegra los motivos de época mediante un discurso donde el logocentrismo salta por los aires. A partir de ese momento, el poeta se adentra en una senda de personalización lírica, desprovisto ya de las apoyaturas generacionales, en Horizonte desde la rada (1983) y De acedia (1986), donde el lenguaje vuelve a creer en si mismo, y se reduce la pretensión vanguardista de sus libros anteriores. Ejercicio sobre Rilke (1988) es una de sus obras más intensas y vitales, que supone una regresión de las preocupaciones metapoéticas, aunque el realismo esencial del mismo está adobado con reverberaciones visionarias y oníricas. Más allá de su referencia pictórica de carácter funeral (La isla de los muertos, de Böcklin), Cantil (1995) es un juego literario muy complejo y laberíntico, cuya gratuidad lúdica deriva al final hacia la reprobación del consumismo capitalista. En Cordura (1999) el poeta se acoge a un estoicismo moral donde se abandonan los antiguos experimentalismos y se abre el hermetismo habitual del autor. En esa línea de claridad está Poeta en diwan (2004), donde la influencia de la lírica madura de Goethe sirve de cañamazo para unos poemas de tono sentencioso y de fuerte sustancia biográfica.

José María Álvarez (1942) es ejemplo de un culturalismo que no se opone a un experiencialismo de base biográfica, por muchas que sean las máscaras superpuestas. De Museo de cera puede decirse que, pese a sus sucesivas ampliaciones desde 1970, en que apareció con el título de 87 poemas, es un libro único caracterizado por la fastuosidad ornamental de los temas: escalinatas y palacios, placeres del cuerpo y del espíritu, lecturas y museos, ruinas. El hiperbólico culturalismo de su universo poético, a veces tejido innecesariamente de citas ajenas que pueden terminar suplantando la voz del poeta, constituye una summa artis, pero también una summa vitce: la de alguien libertino, sibarita y trágico que añora la edad de oro identificada aquí con el libro y con el arte. Con posterioridad ha seguido completando la taracea de un universo abigarrado en libros como El botín del mundo (1994), donde los materiales de aluvión construyen la estampa de un sujeto poético identificable.

Antonio Carvajal (1943) nació como poeta en 1968 con Tigres en el jardín, y ya en el primer momento acotó su territorio: los sonetos alejandrinos evidenciaban su ascendiente modernista, pero no ocultaban la estrecha familiaridad con los líricos andaluces del Barroco español. Libros posteriores revelaban a un autor 
cuya destreza ostensible no ha dejado ver otra maestría más honda, asfixiada entre las joyas formales e imaginativas de sus versos, que no desconocen ningún secreto de escansión ni de estructura. Así, en Serenata y navaja (1973) utiliza el verso libre, en tanto que Casi una fantasia (1975) se dispone como una sonata clásica, con preludio, tema, adagio, scherzo y allegro, en sextetos de factura impecable. El poeta no fue incluido en la antología de los novísimos castelletianos, sin duda porque su primer libro, único publicado hasta 1970, no concordaba ni con el versolibrismo ni con la ruptura habituales en los seleccionados allí, y tampoco con el escepticismo con que abordaban la creación poética. Él es el escritor de lenguaje más barroco de su generación, con abundantes discípulos entre los de promociones siguientes. Libros posteriores como Siesta en el mirador (1979), Sitio de ballesteros (1981), Del idilio y sus horas (1982) y Después que me miraste (1984) profundizan en un mundo lírico donde el amor pasional y la naturaleza tienen lugar de privilegio, siempre timbrados por un regodeo manierista que no desentona de los más acabados artefactos barrocos de sus antecesores áureos, con profusión de versos acrósticos, enumeraciones ordenadas o caóticas, paralelismos, aliteraciones, metáforas. A lo largo de toda su obra, que se ha prolongado en numerosos títulos entre los que destacan Noticia de septiembre (1984), Enero en las ventanas (1986), De un capricho celeste (1988), Testimonio de invierno (1990), Miradas sobre el agua (1993), etc., se ha mantenido su facultad de verter en especie poética la armonía aérea de la música y la maleabilidad plástica de la pintura, aunque la maestría de su escritura, limitando el exhibicionismo, parece haberse puesto al servicio de una envolvente pasión de la carne y de una plenitud vitalista en que se conjuntan el ímpetu erótico y la unción contemplativa.

De los antiguos autores del 68, algunos llegaron a adquirir una presencia pública que antes no habían podido tener, debido a la discordancia entre sus poéticas particulares y las estéticas dominantes. Desde el primer momento hubo quienes dieron muestras de una sensibilidad de rasgos distintos a los más conocidos, o de condición temporalista como Juan Luis Panero, o de talante romántico como Antonio Colinas. Colinas (1946) enlaza con el gran Romanticismo europeo -es traductor y estudioso de Leopardi-, en especial por la ausencia de intermediaciones en la expresión de la emoción amorosa, arqueológica o panteísta. Su defensa de estos valores contiene un juicio negativo acerca de la mayoría de sus contemporáneos: «La vieja lección de Prometeo robando el fuego de la divinidad parece haber sido echada en saco roto por la mayoría de los poetas de nuestros días» (en Martín Pardo, 1990: 53). Dejando a un lado sus libros anteriores a 1975 (Poemas de la tierra y de la sangre, 1969; Preludios a una noche total, 1969; y Truenos y flautas en un templo, 1972), alcanzó su primera plenitud en Sepulcro en Tarquinia $(1975,1976)$, donde el autor insistía, sin renunciar al culturalismo generacional, en el alejamiento de los modelos distanciadores, irónicos, asépticos 
y antisentimentales, y en su cercanía al espíritu romántico y a sus motivos nucleares: panteísmo, ruinas, épica del fracaso. En Sepulcro en Tarquinia están presentes la atracción por los iconos de la cultura a los que tanto caso había hecho el venecianismo, la reviviscencia de un surrealismo tamizado y la emoción humanista. El poema central, que da título al libro, se ordena en series de versos en su mayoría endecasílabos, sin rima, no urdidos según un hilo argumental único. El expolio de una tumba etrusca es el detonante en forma de recuerdo de una historia amorosa, desde la perspectiva del amante y ante la muerte de la amada. En la disposición de los elementos verbales, tendentes a subrayar la triste esencia perecedera de los hombres y del universo, prevalece la anexión oracional mediante afinidades tropológicas, con una libertad surrealista en la confección de las imágenes que hace de éste un poema principal en la poesía del período. Tras él, la poética de Colinas ha ido desplegándose en libros como Astrolabio (1979) y Noche más allá de la noche (1983), treinta y cinco cantos de alejandrinos solemnes y pletóricos donde la experiencia personal está imbricada con un espacio que se abre de lo telúrico a lo órfico. Las sartas salmódicas aparecen, aquí y allá, como un eco oracional, y van disminuyendo en libros posteriores, como Los silencios de fuego (1992), Libro de la mansedumbre (1997), en que predomina una estampa del mundo caracterizada por la compasión contemplativa, y Tiempo y abismo (2002), una caida al origen rilkeana donde destacan sus versos de metrismo enjuto y retórica despoblada.

\section{Poetas recuperados e incorporados}

En los primeros años del posfranquismo, la poesía española de la generación entonces dominante se encontraba en el trance de salir del territorio de escepticismo y negatividad de los primeros sesentayochistas, que había conducido a buena parte de sus representantes al silencio o al cambio de género (muchos, como Vázquez Montalbán, Félix de Azúa, Ana María Moix, etc., se pasaron sin complejos a la novela, donde algunos han hecho fructuosa carrera). En la tarea aportaron su concurso autores como los ya referidos Colinas, Carvajal u otros. Al mismo tiempo que comienzan a surgir poetas de una nueva generación, fueron cobrando relevancia otros coetáneos que, o bien habían carecido de eco pese a que sus primeras obras son de diez o más años atrás, o bien habían aparecido tarde, en un momento en que las propuestas creativas que aportaban podían ya ser bien acogidas.

La publicación en 1975 del Parnasillo provincial de poetas apócrifos supone un anuncio de este cambio. El libro era una regocijante broma de los leoneses Agustín Delgado, Luis Mateo Díez y José María Merino, protagonistas los dos primeros de la oposición de Claraboya a la estética de los novísimos castelletia- 
nos, aunque bien podrían considerarse en diversos aspectos afines a los seniors de talante camp de aquella antología (Martínez Sarrión o Vázquez Montalbán; no a José María Álvarez). A uno de los apócrifos, «Fidel Zancón», se le atribuyen los siguientes versos: «Infame turba / la inane tuba // Oh musa novísima / Oh miss vanidísima» (Delgado, Díez y Merino, 1988: 20); y «Desiderio Carretero Osorio», por su parte, responde en la caracterización de los editores al fácil estereotipo gimferreriano: «Joven pulcro de gustos no contaminados, exquisito, valioso, estetizante, tirando a los deleites del adjetivo ruskiniano, un sí es no es merenguista, y propietario de una cultura acotada con pérgolas de modernismo y guirnaldas de barroco churriguera», además de finalista del Premio Nacional de Poesía «José Antonio Primo de Rivera»y y crítico cinematográfico (ibid.: 23).

Pero lo que en los antiguos componentes de Claraboya aparecía como burla, en otros es ya la actualización de una propuesta creativa. Jesús Munárriz (1940) publicó en 1975 Viajes y estancias, tras lo que se adentraría en un tipo de poesía de compromiso social y humano. En Cuarentena (1977) registró la educación sentimental de su generación, tal como lo hicieran Vázquez Montalbán en su día, pero con una sencillez estilística y una retórica de tono menor. Posteriormente, Munárriz ha cultivado una lírica de compromiso colectivo, abierta a las implicaciones del hombre moderno en una sociedad acomodaticia y atrincherada tras su progreso insolidario. Destacan en ella el equilibrio expresivo y las irisaciones humorísticas, cerca del ejemplo de autores de los cincuenta como J. A. Goytisolo o Ángel González. El rechazo del énfasis declamatorio y de la seriedad catequística, pero también la contención imaginativa, se perciben en títulos como Camino de la voz (1988), Otros labios me sueñan (1992), De lo real y sus análisis (1994), Corazón independiente (1998) o Artes y oficios (2002).

Al cabo, se va instaurando un nuevo compromiso con la realidad, que carecía del tono prescriptivo de los poetas socialrealistas de la postguerra y también de sus expectativas redentoras, y que incorporaba, en unos casos, rasgos humorísticos y jirones de la intimidad sentimental del autor, dentro de una estética realista; $\mathrm{y}$, en otros, una entonación simbolista aunque sin sus derivaciones irracionalistas y surreales. De este modo se hacen habituales la propensión sentimental e irónica, y una visión existencial que se expresa contenida o desdeñosamente, con posos estoicos, tal como proviene del maestro de muchos de ellos Manuel Machado. Ello va unido a una modulación formal clasicista, aun en la utilización del verso libre, y a un universo figurativo sin rupturas ni experimentalismos, lo que algunos críticos han considerado una regresión estética.

Miguel d'Ors (1946), poeta en algunos aspectos de la cuerda manuelmachadiana, aunque con una veta trascendente y religiosa, se dio a conocer con $\mathrm{Del}$ amor, del olvido (1972), libro al que siguieron Ciego en Granada (1975), Codex 3 (1981), Chronica (1982)... Más tarde continuó su copiosa trayectoria, con títulos 
tales como Curso superior de ignorancia, La música extremada, La imagen de su cara o, ya en 1999, Hacia otra luz más pura. En su obra de madurez resplandece un poeta ágil y transparente, radicado en un mundo regido por un Dios providente, de un humor tierno y una sensibilidad que se despliega sobre todo en los temas de la familia, de la vida diaria y de la naturaleza. Hay otros poetas algo más tardíos que se inscriben en esta corriente, donde la fluidez formal de cariz simbolista y becqueriano, así como una gracia anecdótica unida a un lenguaje conversacional, apenas ocultan un existencialismo aflictivo. Entre ellos figuran Fernando Ortiz (1947), con Primera despedida (1978) o Personce (1981), obras a las que seguirían títulos como Vieja amiga, Marzo o Recado de escribir; Javier Salvago (1950), con Canciones del amor amargo y otros poemas (1977), La destrucción o el humor (1980), En la perfecta edad (1982), Variaciones y reincidencias (1985)... y así hasta Ulises (1996). Por razones cronológicas, los dos primeros contribuyen, con la conjunción de algunos coetáneos y poetas más jóvenes, a orientar hacia nuevos derroteros la poesía española tras la etapa de dominación culturalista.

Con este tipo de poetización guardan relación dos corrientes que tendrían gran desarrollo desde mitad de los ochenta. Una es la poesía figurativa, argumental y aun con proclividades prosaicas, que no abomina del humor ni tampoco renuncia a la expresión de la plenitud vital en la dicha y en la tragedia, y cuyo representante más importante es Luis Alberto de Cuenca (1950), quien, después de algunos libros caracterizados por un culturalismo ostentoso (Los retratos, 1971; Elsinore, 1972; Scholia, 1978), dio un giro a su obra, visible sobre todo a partir de La caja de plata (1985), en una senda que continuaría en títulos como El otro sueño (1987), El hacha y la rosa (1993), Animales domésticos (1995), Por fuertes y fronteras (1996), Fiebre alta (1999)... Establece ahí una propuesta poética que huye del trascendentalismo, del experimentalismo, del hermetismo y de la metapoesía, y busca la claridad, el humor, la sensibilidad y la técnica, todo ello acompañado de un sabio sistema de esquivar lo esperable, así como de un vitalismo a prueba de desdichas, según él mismo se encarga de señalar: «Mi poesía es figurativa. Mi poesía se entiende. Mi poesía busca moldes métricos y es, casi siempre, epigramática»; y, líneas después: «La poesía es tan sólo una parte de mi vida. Tengo poco o nada que ver con los poetas para quienes la profesión poética es toda su vida) (en AA. VV., 1998: 395). Luis Antonio de Villena, un poeta afectado en sus comienzos por las mismas fiebres culturalistas que Luis Alberto de Cuenca (Sublime solarium, 1971; Hymnica, 1975; El viaje a Bizancio, 1976), fue evolucionando a partir de los ochenta hacia un realismo prosaísta, en ocasiones atenido al llamado realismo sucio y con un fuerte contenido autobiográfico, con títulos como Marginados (1993), Asuntos de delirio (1996), Celebración del libertino (1998) o Las herejías privadas (2001). 
La otra corriente a que se hacía referencia es la de la poesía elegíaca, en buena parte conectada a la sensibilidad romántica $y$, de entre los españoles del siglo XX, a autores como Cernuda, Gil-Albert o Brines. Juan Luis Panero (1942) ha sido considerado el más cernudiano y el más autobiográfico de los poetas de su generación, y uno de los que han influido más en los autores elegíacos surgidos en los años ochenta, durante los que él iba desgranando su obra. Ha cultivado los poemas que expresan una inserción en lo personal de las consideraciones sobre la escritura y el arte, encarnadas en nombres de escritores vinculados a un concepto moral de la creación. Al primer libro de Juan Luis Panero, publicado en 1968 ( $\mathrm{A}$ través del tiempo), siguieron Los trucos de la muerte (1975) y Desapariciones y fracasos (1978), cuya intensidad poética dependía más del narrativismo vivencial que de los brillos del lenguaje. Pero cuando comenzó a ser tenido más en cuenta, dentro ya de unas nuevas pautas valorativas, es a partir de su obra recapitulatoria Juegos para aplazar la muerte (1984), tras la que publicó Antes que llegue la noche (1985), Galería de fantasmas (1988) o Los viajes sin fin (1993), que se incorporan a su poesía reunida (La memoria y la piedra, 1996), a la que aún habría de sumarse Enigmas y despedidas (1999).

Otros autores de esta tendencia no publican nada antes de 1975; es el caso de Francisco Bejarano, cuyo primer libro, Transparencia indebida, es de 1977. Eloy Sánchez Rosillo (1948), el poeta elegíaco por excelencia del último cuarto del siglo XX, se caracteriza por una nitidez expresiva asombrosa, salvedad hecha de ciertas nebulosas en Maneras de estar solo (1978), su primer libro. En él dejaba, no obstante, constancia de los ingredientes esenciales de su literatura: temporalismo, modulación ajustada, métrica de regusto clásico (aunque no atenida por lo general a estrofas regulares), reducción de la vida a la experiencia de la plenitud y a la reviviscencia poética de la misma cuando esa plenitud ha desaparecido. Es éste su libro más difícil y menos logrado, pues la juventud de un poeta que no utiliza máscaras dificulta la entonación retrospectiva inherente en él. En Páginas de un diario (1981), de un moderado culturalismo, aparecen en lontananza los temas de la pérdida y de la función redentora de la belleza, que se hacen ya evidentes en Elegías (1984), de una capacidad evocatoria purísima, y Autorretratos (1989). La fiebre romántica del absoluto poético es para el autor un sucedáneo de la vida que puede redimir al hombre de su implenitud. En La vida (1996) el esplendor del pasado, reconstruido desde la precariedad del presente, deja su lugar a la percepción del fracaso de la existencia, expuesto con los versos más densos y sombríos de este autor.

Algunos años posterior, Abelardo Linares (1952), además de conocido editor de poesía, mostraba en Mitos (1979; título también de su poesía reunida, 2000) el remanente culturalista del 68 , aunque atemperado por la entonación elegíaca y amorosa, en un envase formal métricamente impecable, de retórica sobria y una 
persistente invitación retrospectiva cuya emoción apenas resulta refrenada por la acabada factura de los poemas. Esas caracteristicas se han mantenido en libros posteriores como Sombras (1986), que inaugura un simbolismo cerrado en compactos alejandrinos neomodernistas; Espejos (1991), donde se acentúan los elementos reflexivos, a veces teñidos de onirismo; y Panorama (1995), que presenta innovaciones formales, como el encadenamiento versicular o las reiteraciones permutatorias. Alfonso López Gradolí (1943) aparece unido a los anteriores en el cultivo de una lírica elegíaca y cernudiana antes de 1975, que compatibilizaba con el cultivo de la poesía experimental (Quizá Brigitte Bardot venga a tomar una copa esta noche, 1971, 1977). Desde El aire sombrio (1975), ambos caminos confluyen en una poesia de excipiente clasicista, pero caracterizada por las yuxtaposiciones frasísticas y la ruptura de la ilación gramatical. Libros como Una muchacha rodeada de espigas (1977), Las señales de fuego (1985), Una sucesión de encuentros (1997) o Los signos de la soledad (2000) enlazan la primitiva nostalgia con los esquemas enunciativos y narrativos, peligrosamente lindantes con el prosaísmo.

Hay autores de difícil vinculación a las poéticas dominantes. Entre ellos figura Aníbal Núñez (1944-1987), traductor de Propercio, Catulo, Rimbaud, Nerval, Mallarmé, Eugénio de Andrade... Si dejamos a un lado 29 poemas (1969), en colaboración con Ángel Sánchez, se dio a conocer como poeta con Fábulas domésticas (1972), que lo conecta a la poesía crítica de entonación irónica de ciertos autores de los cincuenta (Ángel González) y de los seniors castelletianos (Martínez Sarrión), en un momento en que estaba fraguándose la derrota de los mitos de su generación. A partir de ahí Núñez, que parece desoír los cantos de sirena del progreso histórico o artístico, se ocupa de la devastación todavía incipiente de la naturaleza (Naturaleza no recuperable, 1976, 1991), se va abismando gnoseológicamente en una sima cada vez más retraída al lenguaje (Taller del hechicero, 1979; Cuarzo, 1981) o se erige en notario de una vasta desolación de despojos urbanos o antropológicos (Alzado de la ruina, 1983)... Muchas de sus múltiples creaciones se fueron publicando tras su muerte, y pueden leerse reunidas en su Obra poética (1995). Un rasgo central de Aníbal Núñez es la retícula de matizaciones, correcciones y elipsis que enfrían el sentimiento y obturan la fluencia emotiva, fijando la imposible secuencia del sentimiento en unas estampas textuales frías y precisas, como si no estuvieran vinculadas a una sensibilidad autorial. Luis Javier Moreno (1946), de no pocas afinidades electivas con Aníbal Núñez, surgió como poeta tardíamente, con Diecisiete poemas (1978), obra a la que siguieron Época de inventario (1979), 324 poemas breves (1987) y otras muchas. En Cuaderno de campo (1996), donde en efecto trata de las cosas del campo (animales, plantas) y de la historia, muestra su habitual renuencia a la 
obviedad emocional, propia de una poesía cuyo culturalismo se aleja del exhibicionismo, orientado a la reflexión sobre la vida y el arte, en especial la pintura.

El purismo minimalista es la senda por la que transitarían, cada uno con sus particularidades, diversos poetas de los ochenta y noventa, que hacen programa del desprendimiento de la anécdota biográfica, del patetismo, de la elegía, del sensorialismo y de lo ornamental. Algunos de los sesentayochistas más jóvenes contribuyeron a su establecimiento, como Jaime Siles (1951) en sus libros a partir de Canon (1973): Alegoría (1977), Música de agua (1983), Columne (1987)..., aunque luego evolucionó a formas afines a las vertientes más juguetonas de las vanguardias hispánicas (Semáforos, semáforos, 1990). La trayectoria de Andrés Sánchez Robayna (1952), fronterizo con los poetas de la generación siguiente, surgidos en pleno proceso de transición democrática, remite a los espirituales del XVI -sin su simbolismo visionario-, a la precisión sustantiva de Jorge Guillén -sin su entusiasmo- y al minimalismo al que fue apuntando Valente en su obra de madurez, dentro de la estética mallarmeana de la renunciación. Su primer libro, Clima (1978), se plantea como una meditación sobre la palabra, que conjuga su esencia verbal y su capacidad de representación, lejos de las inclinaciones metaliterarias a desenmascarar recursos instrumentales o desmontar códigos lingüísticos, como es frecuente en diversos sesentayochistas. El camino abierto ahí se cierra, en un primer círculo, con Tinta (1981) y La roca (1984), donde llega a la expresión enjuta y a la descripción del universo casi despoblado, al borde de la desaparición de las referencias y hasta de la continuidad verbal. El segundo ciclo se inicia en 1989 con Palmas sobre la losa fría, al que siguen Fuego blanco y Sobre una piedra extrema, y concluye en 1999 con Inscripciones. Se retorna en él, tras la purgación ascética anterior, al discurso con mayores concesiones comunicativas, que va engastando los motivos de una cosmofanía. El libro, tras la duna (2002) es un largo poema en fragmentos que conjuga narratividad e introspección y desglosa, en la línea de Wordsworth (The Prelude), los hitos de un proceso formativo: conciencia del yo, situación en la historia, aprehensión del paisaje, del amor, de la poesía.

Clara Janés (1940) es autora de una lírica caracterizada por la desnudez expresiva, la sutileza musical, el orientalismo espiritualista y el repudio del casticismo temático o expresivo. Ello es visible desde Las estrellas vencidas (1964), y singularmente desde En busca de Cordelia y poemas rumanos (1975), en una senda en la que destacan otros títulos como Libro de las alienaciones (1980), Kampa (1986), Lapidario (1988) o Rosas de fuego (1996). Libros más recientes, como Paralajes y Los secretos del bosque, ambos de 2002, se adentran en la espesura de un universo poblado de simbología mítica, con un lenguaje de cuyo tronco referencial se han desprendido los compromisos sociales, las ramas de la moral, 
los sucesos de la historia. Alguna relación con esta lírica, aunque más vertebrada por el rigor conceptual, tiene la de Pedro Provencio.

Otros autores de formación sesentayochista aparecen frisando o traspasando la barrera de 1980. Miguel Sánchez-Ostiz (1950), escritor desbordante en diversos géneros, presenta una poesía de contextura narrativa, escasa de metáforas, sin grandes alardes ni estructurales ni métricos -a veces usa una prosa que no responde a secuencias rítmicas marcadas-, pero muy eficaz por el mundo del que da cuenta. Su primer libro, Pórtico de la fuga, es de 1979; a partir de él van apareciendo Travesía de la noche (1983), De un paseante solitario (1985), Reinos imaginarios (1986), Invención de la ciudad (1993), Carta de vagamundos (1994), reunidos, con varios inéditos, en La marca del cuadrante (2000). El enigmático sujeto de estos títulos oscila entre dos impulsos vitales: el de la huida del proscrito en su tierra, y el del hölderliniano retorno a la casa -su ciudad, su patria- a la que impreca con pasión. El nutrido simbolismo de Sánchez-Ostiz conforma un museo de la navegación existencial, cuyos cachivaches se presentan en los poemas mediante enumeraciones caóticas: cartularios, gabinetes de marino, navíos errantes, cafetines y burdeles en el puerto, balleneros, mapamundis, cuadernos de bitácora. Así es como corresponde a la pasión viajera, alimentada en la imaginería de Conrad, Dana, Melville, Poe o Stevenson, de donde provienen sus marineros que fatigan los océanos, en una deriva vital fascinante y borrosa.

También reluctante a clasificaciones es Antonio Gracia (1946), cuya obra se inicia con La estatura del ansia (1975), apertura de un ciclo caracterizado por la angustia, la obsesión por la escritura, el fracaso existencial y la locura como destino. En él destacan Palimpsesto (1980), un postumario que avanza a trancas y barrancas por los desfiladeros de la angustia vital y la desazón artística, y Los ojos de la metáfora (1983), donde la palabra del poeta queda varada, tras estertores y balbuceos, en la intransitividad y al fin la afasia. El pensamiento atrofiado y un dolor incompatible ya con el arte y aun con la comunicación lingüística parecían anunciar el silencio definitivo. Sin embargo, tras Fragmentos de identidad (1993), recomposición de toda su obra anterior, el poeta volvió compulsivamente a la poesía en Hacia la luz (1998) y Libro los anhelos (1999). En Reconstrucción de un diario (2001), Gracia abandona el confesionalismo directo y recurre a un alter ego, un viejo y anacrónico caballero de vuelta del amor y de la vida, que garabatea los manuscritos que conforman el diario contenido fragmentariamente en este libro, donde se escuchan consideraciones terminales sobre la muerte, la vida, el fracaso amoroso, la salvación por la belleza: notas todas ellas que persisten en $L a$ epopeya interior (2002) y El himno en la elegia (2002).

El primer libro de Juana Castro (1945) es Cóncava mujer (1978), donde se centra en los universales femeninos que ocuparán parte sustancial de su obra, entre la que también destacan Del dolor y las alas (1985) y Narcisia (1986). El 
afán de acotar el mundo de la femineidad, que no es general en la poesía de otras autoras, aparece también en Ana Rossetti (1950), quien inaugura una línea desautomatizadora de los tópicos del erotismo, mediante la creación de una atmósfera de sensualidad que, ya en el primero de sus libros (Los devaneos de Erato, 1980), alcanza una notable altura simbólica a la que llega mediante la utilización de un imaginario culturalista pagano-cristiano. El ritual litúrgico cristiano, que constituyó la educación sentimental de las muchachas de su edad en la postguerra española, favorece los logros de Devocionario (1986), en la línea de la explotación del deseo, aprovechando y radicalizando la lección hedonista de los poetas de Cántico. Otros libros suyos son Yesterday (1988), Virgo potens (1994) y Punto umbrio (1995).

Diego Jesús Jiménez (1942) tiene evidentes conexiones con el universo moral de los del cincuenta, pero también con la estructura lingüística compleja de los sesentayochistas. Autor, durante los años del franquismo, de libros tan valiosos como La ciudad (1965) y Coro de ánimas (1968), en Bajorrelieve (1990) se ocupa de la intersección entre sujeto y arte, atenidos uno y otro a las limitaciones del medio, y en Itinerario para náufragos (1996) ensaya una reconstrucción de la historia general y de su particular historia -la infancia--, desde la perspectiva del fracaso, siempre con un poderoso fraseo versicular y una rica cosmovisión simbólica. Antonio Hernández (1943) es autor de una dilatada obra, en la que destacan títulos como Con tres heridas yo (1983), Campo lunario (1988), Sagrada forma (1994)... En ellos muestra el avance de un sistema expresivo vinculado a la poesía discursiva donde se cruzan esteticismo de raíz andalucista y humanismo existencial, y una retórica viva que contradice la cristalización en que han incurrido otros poetas.

Este mapa quedaría incompleto sin otros nombres que responden a muy diversas definiciones estéticas. Mario Hernández destaca por la transparencia y tersura de sus creaciones (Tankas del mar y de los bosques, 1994), donde la imaginería poética se congela en admirables piezas de precisión. Alejandro Duque Amusco propende a una verbalidad expansiva de amplio despliegue simbólico (Donde rompe la noche, 1994). También César Antonio Molina es poeta de poderoso simbolismo, articulado entre el componente telúrico y el mítico (Las ruinas del mundo, 1991). Alfonso Vallejo, que ha desembarcado con vitalidad en la poesía desde el teatro, es dueño de un lenguaje nervioso, de imagínería futurista y de una autenticidad destemplada, tal como se evidencia en Claridad en acción (1995), Sol azul (1997) o Plutónico ser (2003). Pedro J. de la Peña ofrece en El soplo de los dioses (1992), Los dioses derrotados (1996) y Los iconos perfectos (2002) sendas reflexiones líricas sobre el viaje, el amor, el sentido del progreso, en unos poemas cuya referencialidad épica aparece teñida de melancolía en este mundo sin dioses. Ricardo Bellveser es autor de diversos títulos en los años 
setenta y ochenta, reunidos en La memoria simétrica (1995), a los que le han seguido otros como Julia en julio (1999) y El agua del abedul (2002), crónica de un viaje que se resuelve en consideraciones antropológicas sobre el retorno odiseico. Manuel Ruiz Amezcua ha reunido en Una verdad extraña $(1995,2002)$ una obra en evolución cognoscitiva y progresiva depuración formal, cuya tersura métrica esconde a veces el espanto, desde el patetismo de Humana raiz (1974) y la indagación metafísica de Dialéctica de las sombras (1979) hasta Donde la huida (2001). Francisco Ruiz Noguera comenzó su escritura con Campo de pluma (1984), un título que remite a Góngora, patrón absoluto en su trayecto creativo, y que es también el de su por entonces obra completa (1997), equilibrada y contenida, a la que más tarde se sumaron El año de los ceros y El oro de los sueños, ambos de 2002. José-Miguel Ullán, uno de los primeros sesentayochistas, dispone en Ardicia (1995) sus poemarios ordenados en una senda que se inicia en el testimonio social y avanza hacia formas más enjutas del decir lírico, tanto discursivo como visual. De presencia mucho más tardía, Rosa Romojaro es autora de los libros Agua de luna (1986), La ciudad fronteriza (1988) y Zona de varada (2001), en los que va definiendo una mirada lírica caracterizada por el extrañamiento, la precisión imaginativa y una retórica que debe tanto al barroquismo del XVII como al purismo del $X X$.

El caso de Víctor Botas (1945-1994) es peculiar, por su decidida voluntad de construir su obra sobre los tópicos clásicos y atendiendo a los cauces grecolatinos de género. Autor tardío, Botas puede incorporar un universo amplio de lecturas sin incurrir en el exhibicionismo culturalista de sus coetáneos más precoces, según se aprecia en libros como Las cosas que me acechan (1979) y Prosopon (1980). En Segunda mano (1982) y Aguas mayores y menores (1985), la absorción de la cultura clasicista llega a un oscurecimiento de su propia personalidad poética, dada a la recreación de los prestigiosos modelos clásicos, casi siempre con el aguijón epigramático y muchas veces con fácil transporte a la actualidad en que se sitúa el escritor. Los libros finales alcanzan el equilibrio entre la creación y el remedo: Historia Antigua (1987), Retórica (1992) y el póstumo Las rosas de Babilonia (1994). Esta capacidad de absorción cultural, en un sentido menos restringido a los clásicos grecolatinos, se da también en quien fuera mentor de Botas, José Luis García Martín (1950). Poeta temprano aunque oculto tras sus tareas antológicas y críticas, en 1998 recopiló su obra publicada, cuyo título, Material perecedero, sitúa al lector ante el concepto de su propia literatura: pavesas de un gran fuego, arte menor, ecos de voces que habrá de apagar el tiempo. Una nueva recopilación selectiva es Mudanza (2004), donde da cabida también a su libro anterior, Al doblar la esquina (2001), cuyas estampas consuetudinarias y anodinas se ven ocasionalmente interrumpidas por las vaharadas del misterio. 


\section{Coda brevísima}

Uno de los sesentayochistas más jóvenes, Jaime Siles, ha argüido que la lírica del siglo XX queda polarizada en torno a dos entidades que se sitúan respectivamente en las vanguardias representadas por el veintisiete, y en la poesía gnoseológica de los cincuenta (Siles, 1991: 14-15). Pudiera ser; pero siempre que entendamos que la historia de la literatura no puede ignorar el eslabonamiento íntimo de sus productos, pues ni siquiera las circunstancias de una guerra civil tronzaron del todo, como en una amplia época se pensó, la cadena de la serie estética. Ya casi nadie discute que muchas presuntas novedades de los primeros sesentayochistas tenían precedentes bien notables en quienes los precedieron. Pero, según puede colegirse de lo dicho, lo que vino después -las diferentes poéticas de autores de los ochenta- no sustituyó a lo que había, sino que se puso a su lado. Cuando los jóvenes de los ochenta pretendieron devorar a los padres, en una inversión históricamente recurrente del mito de Saturno, lo que hicieron fue, velis nolis, organizarles el homenaje a que su aventura poética les había hecho acreedores. 


\section{BIBLIOGRAFÍA}

AA. VV., El último tercio del siglo (1968-1998). Antología consultada de la poesía española, prólogo de José-Carlos Mainer, Visor, Madrid, 1998.

CAMPBell, Federico, Infame turba, Barcelona, Lumen, 1971.

CARnero, Guillermo, «Poesía de postguerra en lengua castellana», Poesía, 2 (1978).

CASADO, Miguel, «Líneas de los novísimos», Revista de Occidente, 86-87 (1988), pp. 204-230.

CASTELlet, José María (ed.), Nueve novisimos poetas españoles, Barcelona, Barral, 1970.

DEBICKI, Andrew, Historia de la poesía española del siglo XX. Desde la modernidad hasta el presente, Madrid, Gredos, 1997.

Delgado, Agustín, Luis Mateo Díez y José María Merino, Parnasillo provincial de poetas apócrifos, Madrid, Endymión, 1988, $2^{a}$ ed. facsimilar (1975).

Equipo Claraboya, Teoría y poemas, Barcelona, El Bardo, 1971.

García Martín, José Luis (ed.), Las voces y los ecos, Madrid, Júcar, 1980.

- Treinta años de poesía española, Renacimiento-Comares, Sevilla-Granada, 1996.

García-Posada, Miguel (ed.), La nueva poesía (1975-1992), Barcelona, Crítica, 1996.

LANZ, Juan José, La llama en el laberinto. Poesia y poética en la generación del 68, Mérida, Editora Regional de Extremadura, 1994.

- (ed.), Antología de la poesia española (1960-1975), Madrid, Espasa Calpe, 1997.

- Introducción al estudio de la generación poética española de 1968, Madrid, Universidad Complutense, 2000.

Luna Borge, José, La generación poética del 70, Sevilla, Qüasyeditorial, 1991.

Martín PArdo, Enrique (ed.), Nueva poesía española (1970). Antología consolidada (1990), Madrid, Hiperión, 1990.

Moral, Concepción G. y Rosa María Pereda (eds.), Joven poesía expañola, Madrid, Cátedra, 1979.

ORDÁs, Sabino (Juan Pedro Aparicio, Luis Mateo Díez y José María Merino), Las cenizas del Fénix, León, Diputación, 1985.

PozAnco, Víctor (ed.), Nueve poetas del resurgimiento, Barcelona, Ámbito, 1976.

PRAT, Ignacio, Contra ti (Notas de un contemporáneo de los novisimos), Granada, Editorial Don Quijote, 1982.

Prieto, Antonio (ed.), Espejo del amor y de la muerte, Madrid, Bezoar, 1971.

Prieto de Paula, Ángel L., Musa del 68. Claves de una generación poética, Madrid, Hiperión, 1996. 
- (ed.), Poetas españoles de los cincuenta, Salamanca, Almar, 2002, $2^{\mathrm{a}}$ ed. ( $1^{\mathrm{a}}$ ed.: Salamanca, Almar, 1995).

Provencio, Pedro (ed.), Poéticas españolas contemporáneas. La generación del 70, Madrid, Hiperión, 1988.

RIBES, Francisco (ed.), Poesia última, Madrid, Taurus, 1963.

SÁnchez TORRE, Leopoldo, La poesía en el espejo del poema, Oviedo, Universidad, 1993.

SILES, Jaime, «Ultimísima poesía española escrita en castellano: rasgos distintivos de un discurso en proceso y ensayo de una posible sistematización», Iberoromania, 34 (1991), pp. 14-15. 